\title{
Litter decomposition rate and soil organic matter quality in a patchwork heathland of southern Norway
}

\author{
G. Certini ${ }^{1}$, L. S. Vestgarden ${ }^{2,3}$, C. Forte $^{4}$, and L. Tau Strand ${ }^{2}$ \\ ${ }^{1}$ Dipartimento di Scienze delle Produzioni Agroalimentari e dell'Ambiente (DISPAA), \\ Università degli Studi di Firenze, Firenze, Italy \\ ${ }^{2}$ Department of Environmental Sciences, Norwegian University of Life Sciences, Ås, Norway \\ ${ }^{3}$ Department of Environmental and Health Studies, Telemark University College, B $\emptyset$, Norway \\ ${ }^{4}$ Istituto di Chimica dei Composti OrganoMetallici (ICCOM), UOS Pisa, CNR, Pisa, Italy \\ Correspondence to: G. Certini (certini@unifi.it)
}

Received: 12 June 2014 - Published in SOIL Discuss.: 15 July 2014

Revised: 23 January 2015 - Accepted: 9 February 2015 - Published: 23 February 2015

\begin{abstract}
Norwegian heathland soils, although scant and shallow, are major reservoirs of carbon (C). We aimed at assessing whether vegetation cover and, indirectly, its driving factor soil drainage are good proxies for soil organic matter (SOM) composition and dynamics in a typical heathland area of southern Norway consisting in a patchwork of three different types of vegetation, dominated by Calluna vulgaris (L.) Hull., Molinia caerulea (L.) Moench, or Sphagnum capillifolium (Ehrh.) Hedw. Such vegetation covers were clearly associated to microtopographic differences, which in turn dictated differences in soil moisture regime, Calluna growing in the driest sites, Sphagnum in the wettest, and Molinia in sites with intermediate moisture.

Litter decomposition was followed over a period of 1 year by placing litterbags filled with biomass from each dominant species in each type of vegetation cover. The composition of the plant material and SOM was investigated using chemical methods and solid-state ${ }^{13} \mathrm{C}$ nuclear magnetic resonance (NMR) spectroscopy.

Litter decomposition was faster for Molinia and Calluna, irrespective of the vegetation cover of the site where they were placed. Sphagnum litter decomposed very slowly, especially under Calluna, where the soil environment is by far more oxidising than under itself. In terms of SOM quality, Calluna covered areas showed the greatest differences from the others, in particular a much higher contribution from lipids and aliphatic biopolymers, apparently related to biomass composition.

Our findings showed that, in the studied environment, litter decomposition rate and SOM composition are actually dependent on vegetation cover and/or soil drainage. On this basis, monitoring changes in the patchwork of vegetation types in boreal heathlands could be a reliable cost-effective way to account for climate-changeinduced modifications to SOM and its potential to last.
\end{abstract}

\section{Introduction}

Heathland vegetation covers approximately $60 \%$ of Norway's land area. Norwegian heathland soils, although scant and shallow, are so rich in organic matter that they represent a stock of carbon (C) at least 1 order of magnitude larger than the aboveground vegetation they sustain (Rosberg et al., 1981). To predict the ecological effects of climate and land use changes, it is essential to understand the nature and environmental dependencies of soil organic matter (SOM) in these widespread systems. In fact, any change influencing their SOM stocks and dynamics may have major consequences for both $\mathrm{C}$ balance and the water quality of lakes and rivers (Stuanes et al., 2008).

Following changes in SOM stocks is not a simple task, and several approaches have been proposed for this purpose (e.g. Johnson and Curtis, 2001; Trumbore, 2009; Chiti et al., 2011). The current common belief is that environmental and biological factors predominate on the molecular struc- 
ture in controlling SOM stability (Kleber, 2010; Kleber et al., 2011; Schmidt et al., 2011); however, in some environments, vegetation cover is a good proxy for soil C dynamics, since it controls the input and quality of litter (De Deyn et al., 2008). In turn, vegetation depends, among other factors, on soil drainage, which also influences litter decay and SOM transformation (Wickland et al., 2010), thus representing another possible proxy for SOM storage.

Although present-day vegetation may be different from that which the underlying SOM originated from (Chambers et al., 1999; Hjelle et al., 2010), many studies have demonstrated that the most active part of SOM is the youngest (e.g. Leavitt et al., 1996; Trumbore, 2000; Chiti et al., 2009). Trumbore (2000) found that the average age of the carbon dioxide $\left(\mathrm{CO}_{2}\right)$ released by decomposition processes in boreal forest soils is 30 years, and $50-60 \%$ of total soil respiration arises from SOM with mean residence time less than 1 year. The dominant contribution of recently synthesised organic matter to soil respiration was also assessed by Certini et al. (2003) for forests in temperate regions. Theoretically, the moister and colder the pedoclimate, the better preserved the dead biomass in soil (Hobbie et al., 2000; Hicks Pries et al., 2013). Hence, the wet boreal heathlands are environments where the investigation of a possible relationship between vegetation covers and SOM dynamics is particularly meaningful. Here, due to the intense leaching, lost dissolved organic C (DOC) may be much older than the respired C (Karltun et al., 2005), rendering any possible relationship between present-day vegetation and bulk SOM quality less clear. Nonetheless, in the uppermost soil, where SOM is younger and less degraded than below, such a relationship is expected to be strong enough.

In southern Norway, heathland areas are in most cases characterised by the alternate occurrence - essentially dictated by the soil drainage, in turn controlled by topography, particle size distribution, and soil depth to bedrock - of three vegetation types, which are dominated by the heather $\mathrm{Cal}$ luna vulgaris (L.) Hull., the moor grass Molinia caerulea (L.) Moench and the peat moss Sphagnum capillifolium (Ehrh.) Hedw. Such different vegetation types are cause and effect of the properties and behaviour of the underlying soil. This is undoubtedly true for the soil profile morphology and the sequence of horizons, generally ranging from the O-E-Bhs soil sequum of Calluna-sustaining podzols to multiple $\mathrm{H}$ horizons consisting histosols where Sphagnum grows (Strand et al., 2008).

In this study we report an in situ investigation of the relationships between vegetation cover, initial litter decay rate and soil organic matter composition for a typical montane heathland area in southern Norway where the alternation between Calluna, Molinia, and Sphagnum occurs on a decametric scale. The objective of the study was to assess whether, in this environment, the current vegetation cover is a good proxy for SOM quality and dynamics. To this end, litter decomposition was followed over a period of 1 year by placing litterbags filled with biomass from each dominant species under each type of vegetation cover, so as to simulate the effects of possible climate-change-induced shift of vegetation on early stages of litter decomposition. Furthermore, the composition of the aboveground biomass and the bulk SOM were investigated by chemical methods and solid-state ${ }^{13} \mathrm{C}$ nuclear magnetic resonance (NMR) spectroscopy.

\section{Materials and methods}

\subsection{Study site}

The study area, Storgama $\left(59^{\circ} 02^{\prime} 47^{\prime \prime} \mathrm{N}, 8^{\circ} 39^{\prime} 37^{\prime \prime} \mathrm{E}\right)$, is located in Telemark county, southern Norway, at an elevation of $560 \mathrm{~m}$ above sea level. The mean annual precipitation in Storgama for the period 1961-1990 was $994 \mathrm{~mm}$, and the mean annual air temperature for the same period was $5.0^{\circ} \mathrm{C}$. Approximately $30 \%$ of the area is barren granite bedrock and boulders, and soil often occurs as pockets in depressions in the bedrock surface (Fig. 1a). The average soil depth generally varies between 10 and $35 \mathrm{~cm}$ but greater thicknesses, up to $100 \mathrm{~cm}$, do occur. According to the US Soil Taxonomy (Soil Survey Staff, 2010), and moving from drier to wetter locations, soils are Lithic Haplorthods, Lithic Udipsamments, Lithic Endoaquents and Lithic Haplosaprists. Although there are some scattered or vaguely grouped Scots pines (Pinus sylvestris L.) and downy birch trees (Betula pubescens Ehrh.), the vegetation is largely dominated by heather ( $\mathrm{Cal}$ luna vulgaris (L.) Hull.) at well-drained sites, peat moss (Sphagnum capillifolium (Ehrh.) Hedw.) at poorly drained sites, and moor grass (Molinia caerulea (L.) Moench) at intermediately drained sites (Fig. 1a and b). These dominant vegetation types are interspersed in the area, forming a patchwork dictated by topography, which in turn is a driving factor of water supply. At the Calluna sites Calluna vulgaris was virtually $100 \%$ of the vegetation cover. At the Molinia sites, some Calluna, Erica (Erica tetralix L.) and Nartecium (Narthecium ossifragum (L.) Huds.) were associated with Molinia caerulea but, on a visual basis, amounted to no more than $5 \%$ of the total cover. At the Sphagnum sites, Sphagnum capillifolium covered the entire surface except for a few scattered individuals of Molinia, Erica and Calluna. Hereafter, we will refer to such vegetation assemblages simply as Calluna, Molinia and Sphagnum, respectively. Further pictures and information on vegetation and soils at Storgama are reported in Strand et al. (2008).

\subsection{Vegetation sampling and analysis}

Three sampling sites per dominant vegetation were chosen within an area of approximately 1 ha. At each location, three soil pits were dug down to bedrock, which was 35 to $50 \mathrm{~cm}$ deep. All the vegetation above the pit had been previously sampled and divided according to species. In the case of $\mathrm{Cal}$ luna, the woody stems and branches were separated from 
(a)
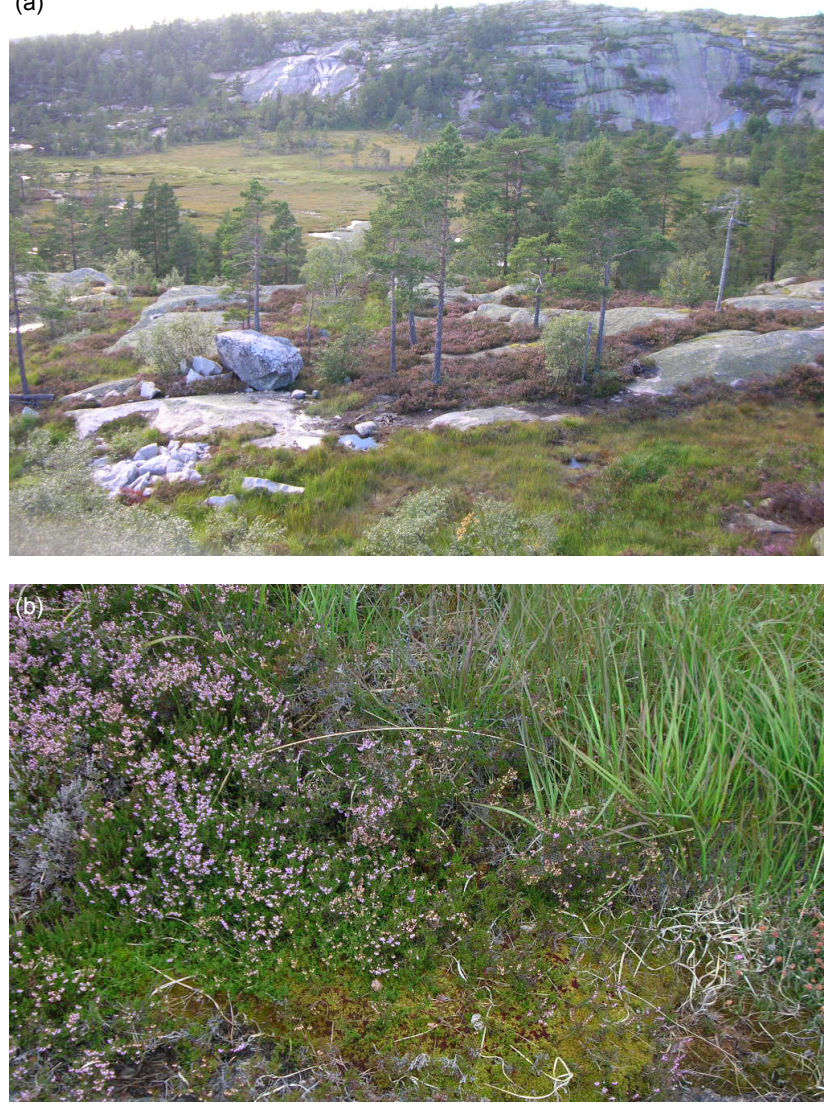

Figure 1. (a) A general view of the study area, Storgama, showing soil occurring in pockets and small depressions at the bedrock surface; note that close-up vegetation at the bottom right is dominated by Molinia caerulea (L.), the understorey of pines beyond is Calluna vulgaris (L.) Hull., and the basin in the background is covered by Sphagnum spp. (b) A rare coalescence of the three dominant species - Calluna vulgaris, on the left; Sphagnum spp. L., at the bottom; and Molinia caerulea, on the right.

the leaves and flowers. Capitula and the upper $5 \mathrm{~cm}$ were used to represent the whole Sphagnum material. Visible roots were picked out from the soil samples and separated according to species when possible. The aboveground biomass and the roots were analysed for $\mathrm{C}$ and $\mathrm{N}$ by means of dry combustion on oven-dried $\left(60^{\circ} \mathrm{C}\right.$ to constant weight) and finely ground samples using a LECO $^{\circledR}$ CHN1000 analyser. The aboveground biomass also underwent NMR investigation.

\subsection{Soil sampling and analysis}

We focused our attention on the uppermost soil layer, where we expected the closest relationship between SOM quality and current vegetation. Two undisturbed soil samples, to be used for soil solution extraction, were taken by completely inserting rigid cylinders $(7.0 \mathrm{~cm}$ high and with $4.6 \mathrm{~cm}$ inner diameter) at about $5 \mathrm{~cm}$ depth in each soil profile. The filled cylinders were carefully extracted from the soil and placed in a cooling box after sealing the ends with plastic lids. The samples were stored at $4{ }^{\circ} \mathrm{C}$, for a maximum of 1 week, until they were processed further. Two standard disturbed soil samples were taken near the holes left by the cylinders and used for $\mathrm{C}, \mathrm{N}$, and $\mathrm{pH}$ determination and NMR analysis. As for the plant material, soil $\mathrm{C}$ and $\mathrm{N}$ concentrations were measured by dry combustion on oven-dried and ground samples, while soil $\mathrm{pH}$ was determined potentiometrically in a $1: 2.5$ $v / v$ distilled water suspension.

The soil-containing cylinders were inserted in twocompartment buckets and centrifuged at $4620 \mathrm{~g}$ for $20 \mathrm{~min}$, following the method described by Giesler et al. (1996). The obtained solution was filtered through a $0.45 \mu \mathrm{m}$ membrane filter (Millipore). An aliquot of the filtrate was analysed for total C (Shimadzu TOC-V element analyser) and, after oxidation by peroxodisulfate (NS4743 1975), for total N (FiaSTAR, Tecator Spectrophotometer system). Another aliquot of the filtrate was used to measure hydrophobicity, which was done by determining the ratio between the absorbances of the solution at 285 and $254 \mathrm{~nm}$ using an UV-VIS spectrophotometer (UV-1201 Shimadzu). These two absorbances are, in fact, correlated to hydrophobic $\mathrm{C}\left(\pi-\pi^{*}\right.$ electron transitions occur at $\sim 285 \mathrm{~nm}$ for a number of aromatic substances, as described in Chin et al., 1994) and total C (Brandstetter et al., 1996), respectively.

After centrifugation the soil was immediately passed through a $2 \mathrm{~mm}$ mesh sieve. Two grams of the moist sieved soil was treated as in the second step of the procedure proposed by Ghani et al. (2003) to obtain hot-water extract $\left(80^{\circ} \mathrm{C}\right.$ for $\left.16 \mathrm{~h}\right)$. After centrifugation for $20 \mathrm{~min}$ at $2000 \mathrm{~g}$ and filtration through $0.45 \mu \mathrm{m}$ membrane filters (Millipore), the extract was analysed for total C (HWC), total N (HWN), and carbohydrate $\mathrm{C}$ (Carb-C). HWC and HWN were determined using the same method as DOC and total dissolved nitrogen (TDN), while the analysis of Carb-C was done according to the "direct determination" method proposed by Safarík and Santrucková (1992). In brief, $1 \mathrm{~mL}$ of the extract was combined in a polyethylene tube with $1 \mathrm{~mL}$ of $5 \%$ phenol solution and $5 \mathrm{~mL}$ of concentrated sulfuric acid and immediately shaken on a vortex mixer. The absorbance of the mixture was read after $1 \mathrm{~h}$ at $485 \mathrm{~nm}$ on a UV-VIS spectrophotometer (UV-1201 Shimadzu). A calibration curve was built with the following standards: $0.00,0.05,0.10,0.25$ and $0.40 \mathrm{~g} \mathrm{~L}^{-1}$ of $\alpha$-D glucose $\left(R^{2}=0.9907\right)$.

\subsection{Nuclear magnetic resonance spectroscopy}

The chemical structure of the aboveground vegetation (one composite sample per dominant species, after removal of stems and coarse branches in the case of Calluna) and SOM (one composite sample per soil pit, hence three samples per vegetation type) was investigated by means of solid-state ${ }^{13} \mathrm{C}$ nuclear magnetic resonance (NMR) spectroscopy using the CP MAS (cross-polarisation with magic-angle spinning) technique. Prior to analysis, soil samples underwent $2 \% \mathrm{HF}$ 
treatment according to Skjemstad et al. (1994) in order to remove possible paramagnetic oxides, which cause broadened resonances and signal loss. NMR spectra were obtained by a Bruker AMX 300-WB spectrometer equipped with a $4 \mathrm{~mm}$ CP MAS probe. The operating frequencies were 300.13 and $75.47 \mathrm{MHz}$ for ${ }^{1} \mathrm{H}$ and ${ }^{13} \mathrm{C}$, respectively; the $\pi / 2$ pulse was $3.4 \mu$ s on the ${ }^{1} \mathrm{H}$ channel. A contact time of $2 \mathrm{~ms}$ and a relaxation delay of $4 \mathrm{~s}$ were used. The MAS speed was set to $8 \mathrm{kHz}$ and the number of scans recorded ranged between 4800 and 40000 , depending on the sample. The chemical shifts were referenced to tetramethylsilane (TMS) using adamantane as external standard. Seven chemical-shift regions of the NMR spectra, corresponding to the main $\mathrm{C}$ forms, were integrated and expressed as percent contribution to total area subtended by the spectrum between 0 and $220 \mathrm{ppm}$. The seven regions account for alkyl C (0-45 ppm, mainly comprising lipids, waxes, resins, suberin), methoxyl and $N$-alkyl C (45-60 ppm, comprising the methoxy group of guaiacyl and the two methoxy groups of syringyl lignin moieties at $\sim 56 \mathrm{ppm}), O$-alkyl C (60-90 ppm, carbohydrates, mainly cellulose and hemicellulose, with contributions from carbohydrate carbons bonded to one oxygen), di- $O$-alkyl C (90-110 ppm, mainly from polysaccharides, with contributions from anomeric carbons of carbohydrates, i.e. bonded to two oxygens), $\mathrm{H}$ - and C-substituted aromatic C (110$140 \mathrm{ppm})$, O-substituted aromatic C (140-162 ppm, mainly from lignin structures, tannins, polyphenols), and carboxyl C (162-190 ppm, esters, acids and amides); no carbonyl intensity in the 190-220 ppm region, ascribable to aldehydes and ketones, was detected.

\subsection{Litter decomposition}

Litter decomposition was determined in situ using the litterbag technique. Recently formed aboveground biomass of Calluna, Molinia and Sphagnum (approximately the top $5 \mathrm{~cm}$ ), were collected at the end of the growing season in late September. This material was oven-dried $\left(35^{\circ} \mathrm{C}\right.$ to constant weight) and used for filling $10 \times 12 \mathrm{~cm}$ nylon mesh bags (0.5-1 mm mesh) with $3.0 \mathrm{~g}$ of Calluna, $2.0 \mathrm{~g}$ of Molinia or $1.0 \mathrm{~g}$ of Sphagnum. In November, 32 litterbags of each vegetation type were installed on the surface of each sampling site, except Calluna under Sphagnum, since a substitution of Calluna by Sphagnum was judged to be highly improbable. Eight to 10 litterbags per type of content were sampled from each site after 6, 9 and 12 months of decomposition. The removed litterbags were cleaned of plant remnants and other minor foreign material by gently using a soft brush and then oven-dried $\left(35^{\circ} \mathrm{C}\right.$ to constant weight) and weighed for determining mass loss. Their content was thus ground and analysed for carbon and nitrogen as described for the vegetation and soil samples.
Table 1. Carbon and nitrogen concentrations and $\mathrm{C} / \mathrm{N}$ ratio of the dominant plant species in the Storgama area. Values in parentheses are standard deviations of six independent replicates. Lower-case letters indicate significant differences $(p<0.05)$, with above- and belowground vegetation treated separately.

\begin{tabular}{llll}
\hline Vegetation & $\begin{array}{l}\mathrm{C} \\
\mathrm{g} \mathrm{kg}^{-1}\end{array}$ & $\begin{array}{l}\mathrm{N} \\
\mathrm{g} \mathrm{kg}^{-1}\end{array}$ & $\mathrm{C} / \mathrm{N}$ ratio \\
\hline Aboveground & & & \\
\hline Calluna leaves and flowers & $536.0(3.2) \mathrm{a}$ & $9.3(1.0) \mathrm{b}$ & $58.3(5.8) \mathrm{b}$ \\
Calluna stems and branches & $522.6(4.8) \mathrm{b}$ & $3.9(0.2) \mathrm{c}$ & $135.6(6.2) \mathrm{a}$ \\
Molinia & $487.0(0.9) \mathrm{c}$ & $16.8(4.1) \mathrm{a}$ & $30.3(7.2) \mathrm{d}$ \\
Sphagnum & $473.9(9.3) \mathrm{d}$ & $11.6(1.2) \mathrm{b}$ & $41.4(5.0) \mathrm{c}$ \\
\hline Belowground & & & \\
\hline $\begin{array}{l}\text { Calluna roots } \\
\text { Molinia } \text { roots }\end{array}$ & $528.6(15.6) \mathrm{a}$ & $9.2(2.6) \mathrm{b}$ & $60.4(13.6) \mathrm{a}$ \\
& $499.9(5.4) \mathrm{b}$ & $15.6(5.2) \mathrm{a}$ & $36.4(15.5) \mathrm{b}$ \\
\hline
\end{tabular}

\subsection{Statistics}

All statistical analyses were performed using the software program SAS (SAS Institute Inc., 1990, Cary, NC). After checking the data set for normality and variance heterogeneity, effects of vegetation and decomposition site on soil $\mathrm{pH}$ and SOM were tested by means of one-way ANOVA (general linear model, GLM). Two separate one-way ANOVAs were performed on litterbags data: one assessing differences in decomposition rate between the three litter types disregarding the dominant vegetation effect, the other assessing differences between the vegetation types disregarding the litter effect. Pairwise comparisons were done by the Tukey's simultaneous test.

\section{Results}

The experimental data set indicated marked differences in composition among the dominant plant species. The $\mathrm{C}$ concentration in the aboveground biomass increased in the order Sphagnum $<$ Molinia $<$ Calluna, whereas the $\mathrm{C} / \mathrm{N}$ ratio increased in the order Molinia $<$ Sphagnum $<$ Calluna, with most interspecific differences being significant (Table 1). Belowground, Calluna and Molinia also showed different composition, hence reflecting the aboveground biomass (Table 1).

Concerning the soil, the measured $\mathrm{pH}$ values, all much below neutrality (Table 2), ensured that all $\mathrm{C}$ present there was in organic forms. The N content of Sphagnum soils was significantly higher than that of Calluna soils, although there were no differences in terms of $\mathrm{C} / \mathrm{N}$ ratio. The latter, clustering around 20, was in all cases much smaller than the $\mathrm{C} / \mathrm{N}$ ratio of the respective dominating plant species.

There was a large variability in soil DOC and TDN concentrations, and vegetation types did not show any significant difference with respect to these two variables (Table 2). However, the hydrophobicity index was significantly different in soils under the three types of vegetation, being highest for Calluna and lowest for Molinia. This difference in- 
Table 2. Selected properties of the topsoil according to dominant vegetation. Values in parentheses are standard deviations of six independent replicates. Lower-case letters indicate significant differences $(p<0.05)$.

\begin{tabular}{lllll}
\hline & & Calluna & Molinia & Sphagnum \\
\hline $\mathrm{pH}$ & & $4.2(0.2)$ & $4.3(0.1)$ & $4.3(0.0)$ \\
$\mathrm{SOC}$ & $\mathrm{g} \mathrm{kg}^{-1}$ & $373.6(140.9)$ & $436.8(101.4)$ & $459.1(7.3)$ \\
$\mathrm{SON}$ & $\mathrm{g} \mathrm{kg}^{-1}$ & $16.3(7.0) \mathrm{b}$ & $22.3(3.1) \mathrm{ab}$ & $25.7(5.0) \mathrm{a}$ \\
$\mathrm{C} / \mathrm{N}$ ratio soil & & $24(5)$ & $20(2)$ & $19(4)$ \\
DOC & $\mathrm{mg} \mathrm{L}^{-1}$ & $86.0(49.2)$ & $174.5(138.3)$ & $53.5(47.5)$ \\
TDN & $\mathrm{mg} \mathrm{L}^{-1}$ & $4.4(3.7)$ & $9.9(9.9)$ & $3.4(3.0)$ \\
C / N ratio soil solution & & $23(7)$ & $27(19)$ & $16(3)$ \\
Hydrophobicity index & & $0.772(0.014) \mathrm{a}$ & $0.692(0.021) \mathrm{b}$ & $0.740(0.015) \mathrm{c}$ \\
HWC & $\mathrm{g} \mathrm{kg}^{-1}$ & $16.3(6.5)$ & $20.7(8.4)$ & $20.7(7.8)$ \\
HWN & $\mathrm{g} \mathrm{kg}^{-1}$ & $0.68(0.34) \mathrm{a}$ & $1.43(0.64) \mathrm{b}$ & $1.54(0.31) \mathrm{b}$ \\
HWC / N ratio & & $26(7) \mathrm{a}$ & $15(3) \mathrm{b}$ & $13(4) \mathrm{b}$ \\
HWcarb-C & $\mathrm{g} \mathrm{kg}^{-1}$ & $8.6(3.9)$ & $11.1(5.0)$ & $10.1(3.8)$ \\
HWcarb-C / HWC & $\%$ & $52(4)$ & $52(11)$ & $49(7)$ \\
\hline
\end{tabular}

SOC: soil organic carbon; SON: soil organic nitrogen; DOC: dissolved organic carbon; TDN: total dissolved nitrogen; Hydrophobicity index: hydrophobicity index of soil solution; HWC: carbon in the hot-water extract; HWN: nitrogen in the hot-water extract; HWC / N ratio: carbon to nitrogen ratio in the hot-water extract; HWcarb-C: carbohydrate carbon in the hot-water extract; HWcarb-C / HWC: percent carbohydrate carbon to total carbon in the hot-water extract.

dicates that a greater proportion of DOC under Calluna was hydrophobic. For the rest, the only other significant differences were in terms of $\mathrm{HWN}$ and $\mathrm{HWC} / \mathrm{N}$ ratio between Calluna, on the one hand, and Molinia and Sphagnum, on the other (Table 2).

The ${ }^{13} \mathrm{C}$ CP MAS NMR spectra of the aboveground biomass and soil are shown in Fig. 2, and the relative contributions of the different chemical shift regions are reported in Table 3. The NMR spectra of the aboveground vegetation suggested more similar compositions for Molinia and Sphagnum with respect to Calluna. The spectrum of the Calluna biomass was dominated by signals between 60 and $104 \mathrm{ppm}$, characteristic of polysaccharides; the relatively high intensity in the alkyl $\mathrm{C}$ region $(0-50 \mathrm{ppm})$ was due to lipids and aliphatic biopolymers. The spectrum also revealed the presence of lignin and tannins, as indicated by the lignin methoxyl carbon signal at $56 \mathrm{ppm}$, and the distinct aromatic peaks at 145 and $155 \mathrm{ppm}$, typical of condensed tannins. The sharp peak at $172 \mathrm{ppm}$ is normally assigned to the carboxyl $\mathrm{C}$ of hemicellulose esters, but may also have contributions from amides (Forte et al., 2006). The spectra of Molinia and Sphagnum aboveground biomasses showed the same dominant polysaccharide features of Calluna in the 50-110 ppm range, but a significantly lower intensity of signal in the alkyl and aromatic $\mathrm{C}$ regions, which means lower contribution of lipids and lignin/tannins, respectively. In the case of Molinia, the slightly narrower signals in the $60-100 \mathrm{ppm}$ region and the relatively smaller peak shoulder at about 103 ppm compared with both Calluna and Sphagnum suggested the occurrence of less hemicellulose and some crystalline cellulose, respectively. Sphagnum did not show the typical lignin signals, in agreement with the common lignin-free composition of bryophytes (Klavinga et al., 2012). The only aromatic sig- nals in the sphagnum spectrum were due to unsubstituted or $\mathrm{C}$-substituted aryl $\mathrm{C}$ at 117 and $130 \mathrm{ppm}$, while the signal at $158 \mathrm{ppm}$ was ascribable to phenolic structures. In the case of Calluna, the two sharp tannin peaks at 145 and $155 \mathrm{ppm}$ observed in the aboveground biomass spectrum were totally absent in the SOM spectrum. In the case of Molinia, differently from the other two vegetation types, the relative contribution of aromatic C significantly increased in soil compared to that observed in the aboveground biomass. In the case of Sphagnum, no major changes occurred in the aromatic region, except for the absence in the soil spectrum of the signal at $158 \mathrm{ppm}$ detected for the aboveground vegetation (Fig. 2). The alkyl C / $O$-alkyl C ratio increased for all vegetation types on passing from the intact biomass to its decomposition products in soil (Table 3), with large differences in absolute values between Calluna, on the one hand, and Molinia and Sphagnum, on the other.

The in situ decomposition study using litterbags showed that the litter mass remaining after 1 year of decomposition varied between 62 and $66 \%$ in the case of Molinia and Calluna and 83 and $94 \%$ for Sphagnum (Fig. 3). The discrepancy between the couple Calluna-Molinia and Sphagnum was lower, although significant, in the intermediate stages of the experiment. After 6 months, Calluna showed significantly lower mass loss than Molinia under itself, while, at the end of the experiment Calluna, resulted in being better preserved than Molinia only under Molinia (Fig. 3).

In terms of relative $\mathrm{C}$ content of the residual litter, $\mathrm{Cal}$ luna did not change throughout the 12 months of the experiment, while Molinia and Sphagnum experienced a marked decrease compared to the original value (Fig. 4). Concentrations of $\mathrm{N}$ in the litter changed more than the $\mathrm{C}$ ones. Except for Sphagnum under itself or under Molinia, all litters 
Table 3. Relative intensities, expressed as percent of total area between 0 and $190 \mathrm{ppm}$, of seven main chemical shift regions of CP MAS

${ }^{13} \mathrm{C}$ NMR spectra and the ratio between the alkyl C and the $O$-alkyl C-related signals for aboveground vegetation and topsoil.

\begin{tabular}{|c|c|c|c|c|c|c|c|c|c|}
\hline Vegetation & Sample & $\begin{array}{l}\text { Alkyl C } \\
(0-45 \text { ppm })\end{array}$ & $\begin{array}{l}\text { Methoxyl and } \\
N \text {-alkyl C } \\
\text { (45-60 ppm) }\end{array}$ & $\begin{array}{l}O \text {-alkyl C } \\
(60-90 \mathrm{ppm})\end{array}$ & $\begin{array}{l}\text { di- } O \text {-alkyl C } \\
(90-110 \text { ppm })\end{array}$ & $\begin{array}{l}\mathrm{H}-, \mathrm{C}- \\
\text { substituted } \\
\text { aromatic C } \\
(110-140 \mathrm{ppm})\end{array}$ & $\begin{array}{l}\text { O-substituted } \\
\text { aromatic C } \\
(140-162 \mathrm{ppm})\end{array}$ & $\begin{array}{l}\text { Carboxyl C } \\
(162- \\
190 \mathrm{ppm})\end{array}$ & $\begin{array}{l}\text { Alkyl C / } O \text { - } \\
\text { alkyl C } \\
(0-45 \mathrm{ppm} / \\
60-110 \mathrm{ppm})\end{array}$ \\
\hline \multirow[t]{2}{*}{ Calluna } & Aboveground & 24 & 6 & 39 & 11 & 7 & 7 & 6 & 0.5 \\
\hline & $\begin{array}{l}\text { Top } 10 \mathrm{~cm} \\
\text { soil }^{*}\end{array}$ & $42 \pm 1$ & $8 \pm 1$ & $29 \pm 3$ & $7 \pm 1$ & $8 \pm 1$ & $2 \pm 1$ & $4 \pm 1$ & $1.2 \pm 0.1$ \\
\hline \multirow[t]{2}{*}{ Molinia } & Aboveground & 12 & 8 & 51 & 14 & 8 & 3 & 4 & 0.2 \\
\hline & $\begin{array}{l}\text { Top } 10 \mathrm{~cm} \\
\text { soil }^{*}\end{array}$ & $28 \pm 5$ & $9 \pm 1$ & $33 \pm 4$ & $8 \pm 1$ & $11 \pm 1$ & $5 \pm 1$ & $6 \pm 1$ & $0.7 \pm 0.2$ \\
\hline \multirow[t]{2}{*}{ Sphagnum } & Aboveground & 13 & 7 & 51 & 14 & 8 & 2 & 5 & 0.2 \\
\hline & $\begin{array}{l}\text { Top } 10 \mathrm{~cm} \\
\text { soil }^{*}\end{array}$ & $30 \pm 10$ & $7 \pm 2$ & $36 \pm 10$ & $8 \pm 2$ & $9 \pm 1$ & $3 \pm 1$ & $7 \pm 2$ & $0.7 \pm 0.3$ \\
\hline
\end{tabular}

* These values are means of three independent samples \pm standard deviation.

Calluna

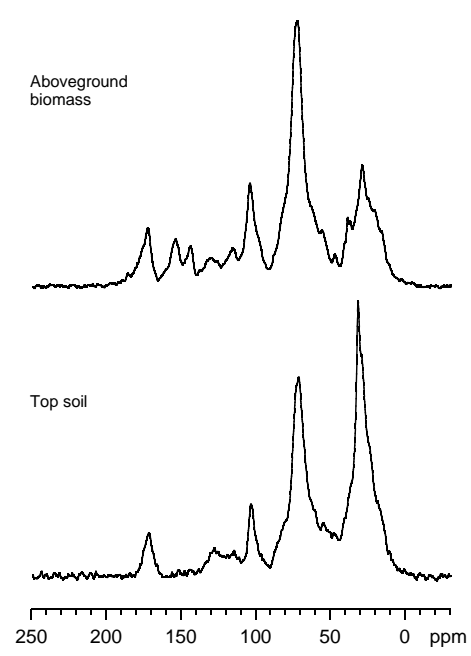

Molinia

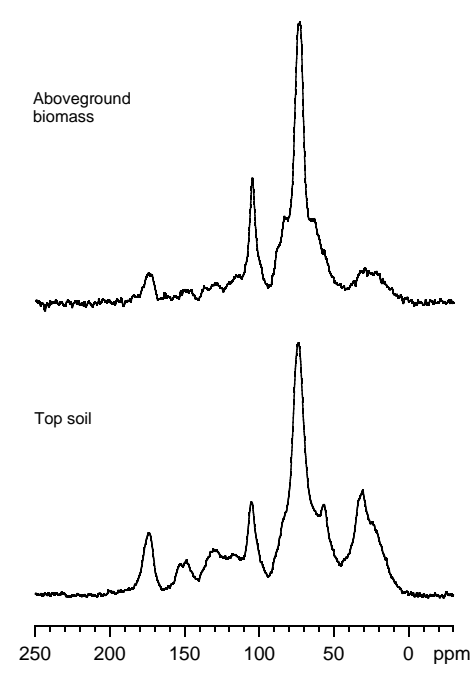

Sphagnum

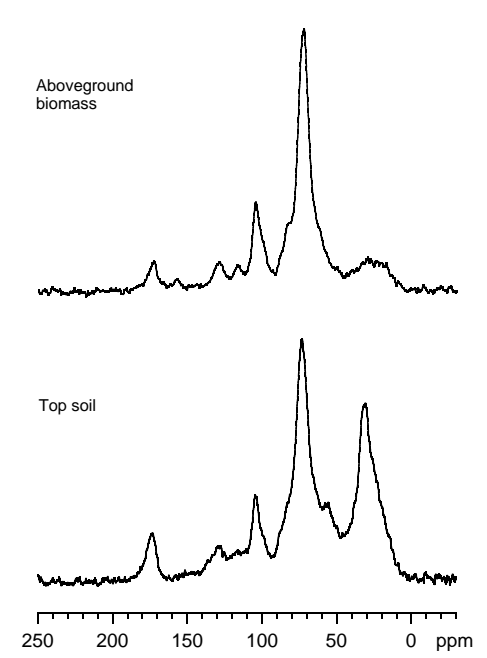

Figure 2. ${ }^{13} \mathrm{C}$ CP MAS NMR spectra of the aboveground biomass of the dominant plant species and soil.

increased their relative $\mathrm{N}$ content from November to May; later, all of them increased until August, with the exception of Sphagnum under Calluna and Molinia under itself; and finally, in the period from August to November, N concentration continued to increase in Calluna, whereas it decreased in Molinia and showed an irregular trend in Sphagnum (Fig. 4). These $\mathrm{C}$ and $\mathrm{N}$ trends implied progressive, although slight, decrease in C / N ratio for Calluna and Sphagnum, and a sharper decrease for the same ratio for Molinia until August, after which it increased (Fig. 4). Contrary to Calluna and Sphagnum, Molinia degraded maintaining significantly higher values of $\mathrm{C} / \mathrm{N}$ ratio under Sphagnum than under the other types of vegetation (Molinia and Calluna). At the end of the experiment, in November, the $\mathrm{C} / \mathrm{N}$ ratio in Molinia under Sphagnum was even higher than the original value.

\section{Discussion}

In the heathland environment of Storgama, the composition of SOM appeared to partly reflect that of the parent vegetation. Hence, for example, the abundance of alkyl $\mathrm{C}$ in the Calluna biomass relative to the other two vegetation types was transferred to the SOM. Nevertheless, SOM accumulated over a long period of time; as a consequence, it could be the result of multiple changes in vegetation cover in the area and thus be partly unrelated to the current vegetation cover. Moreover, inputs of wind-blown or water-transported material cannot be excluded at any site, although there was no direct or indirect evidence in this regard.

Sphagnum showed a composition potentially more prone to decay than Calluna and Molinia. Nevertheless, there were no significant differences in the SOM content of the topsoil of the three vegetation covers. Evidently, the prevailing anoxic conditions limited decomposition at the Sphagnum sites. This is in accordance with several studies that used 


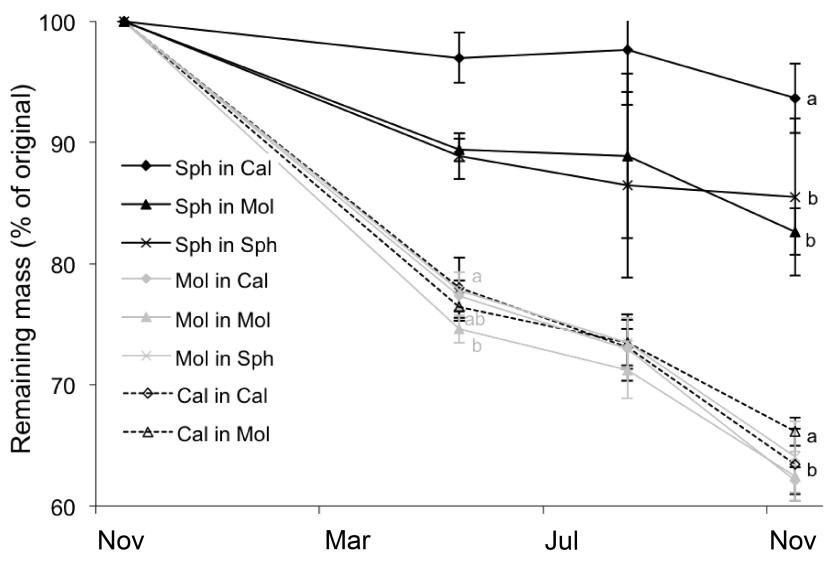

Figure 3. Residual mass in the litterbags as a function of time for different combinations of litter and vegetation cover. "Cal in Cal" means Calluna litter decomposing under Calluna, "Cal in Mol" means Calluna litter decomposing under Molinia, and so on. Error bars are standard deviations, while lower-case letters indicate significant differences $(p<0.05)$ between same litters decomposing under different types of vegetation. The trial was 1 year long.

the type of vegetation cover as a proxy for carbon dynamics, based on the consideration that vegetation chiefly reflects the soil moisture regime (Bridgham et al., 2008; Couwenberg et al., 2011; Delarue et al., 2011), which is in turn a driving factor of litter decomposition (Hobbie et al., 2000; Laiho, 2006). Large variability in DOC concentrations and no significant effect of vegetation was observed (Table 2). It must be noted, however, that our study shows the conditions only at one sampling occasion, i.e. at the end of the growing season, when DOC concentrations are affected by a considerable contribution from senescing plant material. The measured DOC concentrations were generally in agreement with those recorded in autumn using zero-tension lysimeters in soils at Storgama and other Norwegian heathland areas (Strand et al., 2002; Vestgarden et al., 2010), although DOC concentrations in centrifuged and freely drained soil solutions are not directly comparable (Giesler et al., 1996). Similarly to DOC, TDN showed a large variability and no apparent correlation with vegetation. The relatively small amount of water extracted by centrifugation limited the number of possible analyses, preventing $\mathrm{N}$ speciation. TDN therefore included both organic $\mathrm{N}$ and inorganic $\mathrm{N}$, the latter amounting to $25-50 \%$ of TDN in soil water from southern Norway (Austnes et al., 2008; Kaste et al., 2008).

The hydrophobicity index of soil water differed significantly among vegetation types. Apparently, Calluna released DOC with the highest proportion of hydrophobic organic compounds, perhaps mostly arising from tannins and decomposition of lignin (Dilling and Kaiser, 2002), which are indeed important components of the Calluna litter (Fig. 2).

Hot-water C approximately amounted to $4.5 \%$ of SOC in all samples, irrespective of vegetation. This percentage is in the range reported by von Lützow et al. (2007). Significantly lower amounts of HWN were extracted from the Calluna soils compared to the Molinia and Sphagnum ones, which also implied a significantly higher HWC / HWN ratio for Calluna (Table 2). We did not partition HWN; however, Curtin et al. (2006) demonstrated that it is mainly organic and, in suborder, $\mathrm{NH}_{4}-\mathrm{N}$ generated by hydrolysis of heat-labile organic $\mathrm{N}$. The quality of the hot-water extract rather well discriminated Calluna from Molinia and Sphagnum. Some authors have proposed hot-water extraction of SOM as a method to measure the labile SOM pool (Chodak et al., 2003; Ghani et al., 2003; Curtin et al., 2006); however, other authors consider this method not selective enough for this purpose (Landgraf et al., 2006; von Lützow et al., 2007). In our case, approximately half the $\mathrm{C}$ extracted by hot water belonged to carbohydrates.

The NMR spectra showed clear structural differences in aboveground plant material (Fig. 2 and Table 3). In particular, Calluna was richer in alkyl $\mathrm{C}$ and poorer in $O$-alkyl C than Molinia and Sphagnum, as was reflected in the alkyl C / $O$ alkyl $\mathrm{C}$ ratio. The richness in alkyl $\mathrm{C}$ has been correlated to slow decomposition rates in heathland ecosystems (van $\mathrm{Vu}$ uren and van der Eerden, 1992; van Vuuren and Berendse, 1993). However, in our litterbag experiment there were small and variable differences between the mass losses of Calluna and Molinia, and both of them were much higher than the one in Sphagnum wherever the latter was placed (Fig. 3). A possible explanation for such short-term resistance of Sphagnum to degradation could be that this type of vegetation is particularly rich in sphagnan pectin-like polysaccharides, which, unlike the other types of polysaccharides, induce processes that prevent organic matter decay (Hájek et al., 2011; Ballance et al., 2012). Moreover, it must be considered that Sphagnum might have experienced a "non-additive" pattern of mass loss, i.e. a decomposition behaviour sometimes observed in litter mixes that deviates from the response predicted for the individual species because of the influence of the other species present in the mix (Gartner and Cardon, 2004). In this case, the necromasses of Molinia and, in particular, Calluna could have partly inhibited the decomposition of the Sphagnum in the litterbags.

In addition to a "vegetation effect", the litterbag experiment showed some "site effect", i.e. more rapid decomposition when litter was placed beneath the parent vegetation rather than beneath other species (Ayres et al., 2009; Perez et al., 2013; Wang et al., 2013). In fact, for Sphagnum the mass loss was significantly lower when it decayed under Calluna than under Molinia or Sphagnum (Fig. 3). Calluna was better preserved under Molinia than under itself at the end of the trial, while, after 6 months only, Molinia litter showed a significant environment-induced advantage under Sphagnum compared to under itself (Fig. 3). Unexpectedly, the welldrained Calluna soils preserved Sphagnum and Molinia from decay better than the moister soils where they were growing, perhaps as an effect of a seasonal drought. 

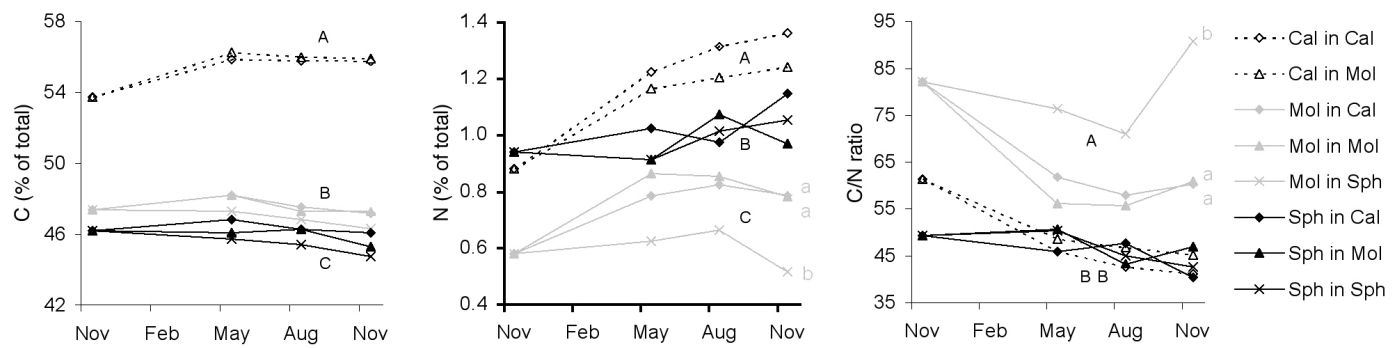

Figure 4. Carbon and nitrogen concentrations and $\mathrm{C} / \mathrm{N}$ ratio in decaying biomass in the litterbags as a function of time for different combinations of litter and vegetation cover. "Cal in Cal" means Calluna litter decomposing in soil under Calluna, "Cal in Mol" means Calluna litter decomposing under Molinia, and so on. Upper-case letters indicate significant differences $(p<0.05)$ between different litters, whereas lower-case letters indicate significant differences between same litters decomposing in soils covered by different types of vegetation.

The enclosure of litter inside mesh bags may actually change its overall decomposition rate and its $\mathrm{C}$ and $\mathrm{N}$ percent concentrations compared to non-bagged substrate (Berhe, 2013). In our experiment, however, we must confidently assume that such a bagging effect is uniform through the samples, and that also because the bags are very similar. On this basis, Molinia showed an initial C / N ratio much higher than the ones of Calluna and, especially, Sphagnum (Fig. 4), which suggested a more marked intrinsic resistance of Molinia to decay. Noteworthy is the difference in $\mathrm{C} / \mathrm{N}$ ratio between the aboveground Molinia biomass analysed for basic characterisation (data of Table 1) and the Molinia used in the litterbag experiment (30 vs. circa 80). Molinia is a grass that wilts at the end of the growing season, when we sampled the material to be inserted in the bags, while the Molinia sampled for basic characterisation was still with active photosynthesis, when the $\mathrm{C} / \mathrm{N}$ ratio is relatively low (Taylor et al., 2001). On the other hand, Calluna is evergreen and no great seasonal changes in $\mathrm{C}$ and $\mathrm{N}$ concentrations occur, while Sphagnum, although it is not evergreen, does not wilt and its $\mathrm{C} / \mathrm{N}$ ratio is rather constant throughout the year. Our litterbag experiment showed that the $\mathrm{C} / \mathrm{N}$ ratio is a poor predictor of decay in this environment. The anoxic conditions imposed by prolonged water saturation, commonly occurring in the Sphagnum soils and expected to have considerable influence in slackening litter decomposition, appeared, however, to be irrelevant in preserving organic residues during a 1-year-long experiment (Fig. 3). In this regard, during a 3-year study in heathlands on Molinia caerulea and Erica tetralix, van Vuuren and Berendse (1993) did not find any site effect and litter quality appeared to be the sole driving factor. Also, Scheffer et al. (2001), studying the decomposition process in fens dominated by Sphagnum species or without Sphagnum, concluded that decomposition was controlled more by intrinsic differences in litter quality than by the environment.
The NMR investigation revealed that soils, compared to the litter they receive, showed significantly higher contribution of alkyl C and lower contribution of $O$-alkyl C (Fig. 2 and Table 3), most probably as a result of a faster decay of carbohydrates than of other $\mathrm{C}$ forms and the synthesis of lipids from the biodegradation of carbohydrate and aromatic fractions (Baldock et al., 1992). The alkyl C / $O$-alkyl $\mathrm{C}$ ratio, which generally increases as decomposition proceeds, was significantly higher in the Calluna soil than under Molinia and Sphagnum.

\section{Conclusions}

We found that, in the varied heathland of Storgama, there were many significant differences in terms of SOM composition between the Calluna-dominated areas and the interspersed Sphagnum-covered areas. Most differences were clearly due to the litter quality. A "vegetation effect" on the early stage of litter decomposition rate was clear, Sphagnum remnants being much more stable independently of the environmental conditions they underwent, which differed especially in terms of soil drainage. Hence, overall, vegetation appeared to be a good proxy for SOM quality. On this basis, monitoring the distribution of vegetation types in heathlands of Norway and elsewhere could be of particular interest for assessing the consequences of climate change on SOM stocks and dynamics. In the plausible scenario of a less continuous rainfall supply and a consequent contraction of Sphagnum-covered areas, the Sphagnum-released litter seems to have good short-term ability to resist decomposition under the two replacing types of vegetation: Molinia and Calluna. Long-term experiments addressing this issue are needed. 
Acknowledgements. We thank Irene Eriksen Dahl, Grete Bloch, and Ivan Digernes for laboratory assistance at the Department for Plants and Environmental Sciences, Norwegian University of Life Sciences. We also thank Silvia Pizzanelli of ICCOM-CNR for performing part of the NMR analyses and the editor and reviewers for their constructive comments.

The study was carried out in close cooperation with the CLUE project (NFR 155826/S30). This specific investigation was made possible by a grant from the Research Council of Norway (NFR $164903 /$ S30) enabling the first author to cooperate with researchers from the Norwegian University of Life Sciences.

Edited by: A. A. Berhe

\section{References}

Austnes, K., Kaste, O., Vestgarden, L. S., and Mulder, J.: Manipulation of snow in small headwater catchments at Storgama, Norway: Effects on leaching of total organic carbon and total organic nitrogen, Ambio, 37, 38-47, 2008.

Ayres, E., Steltzer, H., Simmons, B. L., Simpson, R. T., Steinweg, J. M., Wallenstein, M. D., Mellor, N., Parton, W. J., Moore J. C., and Wall, D. H.: Home-field advantage accelerates leaf litter decomposition in forests, Soil Biol. Biochem., 41, 606-610, 2009.

Baldock, J. A., Oades, J. M., Waters, A. G., Peng, X., Vassallo, A. M., and Wilson, M. A.: Aspects of the chemical structure of soil organic materials as revealed by solid-state ${ }^{13} \mathrm{C}$ NMR spectroscopy, Biogeochemistry, 16, 1-42, 1992.

Ballance, S., Kristiansen, K. A., Skogaker, N. T., Tvedt, K. E., and Christensen, B. E.: The localisation of pectin in Sphagnum moss leaves and its role in preservation, Carbohyd. Polym., 87, 13261332, 2012.

Berhe, A. A.: Effect of litterbags on rate of organic substrate decomposition along soil depth and geomorphic gradients, J. Soils Sediments 13, 629-640, 2013.

Brandstetter, A., Sletten, R. S., Mentler, A., and Wenzel, W. W.: Estimating dissolved organic carbon in natural waters by UV absorbance (254 nm), Z. Pflanz. Bodenkunde, 159, 605-607, 1996.

Bridgham, S. D., Pastor, J., Dewey, B., Weltzin, J. F., and Updegraff, K.: Rapid carbon response of peatlands to climate change, Ecology, 89, 3041-3048, 2008.

Certini, G., Corti, G., Agnelli, A., and Sanesi, G.: Carbon dioxide efflux and concentrations in two soils under temperate forests, Biol. Fert. Soils, 37, 39-46, 2003.

Chambers, F. M., Mauquoy, D., and Todd, P. A.: Recent rise to dominance of Molinia caerulea in environmentally sensitive areas: new perspectives from palaeoecological data, J. Appl. Ecol., 36, 719-733, 1999.

Chin, Y. P., Aiken, G., and Oloughlin, E.: Molecular-weight, polydispersity, and spectroscopic properties of aquatic humic substances, Environ. Sci. Technol., 28, 1853-1858, 1994.

Chiti, T., Neubert, R. E. M., Janssens, I. A., Certini, G., Curiel Yuste, J., and Sirignano, C.: Radiocarbon dating reveals different past managements of adjacent forest soils in the Campine region, Belgium, Geoderma, 149, 137-142, 2009.

Chiti, T., Certini, G., Perugini, L., Mastrolonardo, G., Papale, D., and Valentini, R.: Soil carbon dynamics in a Mediterranean forest during the Kyoto Protocol commitment periods, Reg. Environ. Change, 11, 371-376, 2011.
Chodak, M., Khanna, P., and Beese, F.: Hot water extractable C and $\mathrm{N}$ in relation to microbiological properties of soils under beech forests, Biol. Fert. Soils, 39, 123-130, 2003.

Couwenberg, J., Thiele, A., Tanneberger, F., Augustin, J., Barisch, S., Dubovik, D., Liashchynskaya, N., Michaelis, D., Minke, M., Skuratovich, A., and Joosten, H.: Assessing greenhouse gas emissions from peatlands using vegetation as a proxy, Hydrobiologia, 674, 67-89, 2011.

Curtin, D., Wright, C. E., Beare, M. H., and McCallum F. M.: Hot water-extractable nitrogen as an indicator of soil nitrogen availability, Soil Sci. Soc. Am. J., 70, 1512-1521, 2006.

De Deyn, G. B., Cornelissen, J. H. C., and Bardgett, R. D.: Plant functional traits and soil carbon sequestration in contrasting biomes, Ecol. Lett., 11, 516-531, 2008.

Delarue, F., Laggoun-Defarge, F., Disnar, J. R., Lottier, N., and Gogo, S.: Organic matter sources and decay assessment in a Sphagnum-dominated peatland (Le Forbonnet, Jura Mountains, France): impact of moisture conditions, Biogeochemistry, 106, 39-52, 2011.

Dilling, J. and Kaiser, K.: Estimation of the hydrophobic fraction of dissolved organic matter in water samples using UV photometry, Water Res., 36, 5037-5044, 2002.

Forte, C., Piazzi, A., Pizzanelli, S., and Certini, G.: CP MAS C-13 spectral editing and relative quantitation of a soil sample, Solid State Nucl. Mag., 30, 81-88, 2006.

Gartner, T. B. and Cardon, Z. G.: Decomposition dynamics in mixed-species leaf litter, Oikos, 104, 230-246, 2004.

Ghani, A., Dexter, M., and Perrott, K. W.: Hot-water extractable carbon in soils: a sensitive measurement for determining impacts of fertilisation, grazing and cultivation, Soil Biol. Biochem., 35, 1231-1243, 2003.

Giesler, R., Lundstrom, U. S., and Grip, H.: Comparison of soil solution chemistry assessment using zero-tension lysimeters or centrifugation, Eur. J. Soil Sci., 47, 395-405, 1996.

Hájek, T., Ballance, S., Limpens, J., Zijlstra, M., and Verhoeven, J. T. A.: Cell-wall polysaccharides play an important role in decay resistance of Sphagnum and actively depressed decomposition in vitro, Biogeochemistry, 103, 45-57, 2011.

Hicks Pries, C. E., Schuur, E. A. G., Vogel, J. G., and Natali, S. M.: Moisture drives surface decomposition in thawing tundra, J. Geophys. Res.-Biogeo., 118, 1133-1143, 2013.

Hjelle, K. L., Halvorsen, L. S., and Overland, A.: Heathland development and relationship between humans and environment along the coast of western Norway through time, Quaternary Int., 220, 133-146, 2010.

Hobbie, S. E., Schimel, J. P., Trumbore, S. E., and Randerson, J. R.: Controls over carbon storage and turnover in high-latitude soils, Glob. Change Biol., 6 (Suppl. 1), 196-210, 2000.

Johnson, D. W. and Curtis, P. S.: Effects of forest management on soil C and N storage: meta-analysis, Forest Ecol. Manag., 140, 227-238, 2001.

Karltun, E., Harrison, A. F., Alriksson, A., Bryant, C., Garnett, M. H., and Olsson, M. T.: Old organic carbon in soil solution DOC after afforestation - evidence from C-14 analysis, Geoderma, 127, 188-195, 2005.

Kaste, O., Austnes, K., Vestgarden, L. S., and Wright, R. F.: Manipulation of snow in small headwater catchments at Storgama, Norway: Effects on leaching of inorganic nitrogen, Ambio, 37, 29-37, 2008. 
Kļaviņa, L., Bikovens, O., Šteinberga, I., Maksimova, V., and Eglìte, L.: Characterization of chemical composition of some bryophytes common in Latvia, Environ. Exp. Biol., 10, 27-34, 2012.

Kleber, M.: What is recalcitrant soil organic matter?, Environ. Chem., 7, 320-332, 2010.

Kleber, M., Nico, P. S., Plante, A., Filley, T., Kramer, M., Swanston, C., and Sollins, P.: Old and stable soil organic matter is not necessarily chemically recalcitrant: implications for modeling concepts and temperature sensitivity, Glob. Chang. Biol., 17, 10971107, 2011.

Laiho, R.: Decomposition in peatlands: Reconciling seemingly contrasting results on the impacts of lowered water levels, Soil Biol. Biochem., 638, 2011-2024, 2006.

Landgraf, D., Leinweber, P., and Makeschin, F.: Cold and hot waterextractable organic matter as indicators of litter decomposition in forest soils, J. Plant Nutr. Soil Sci., 169, 76-82, 2006.

Leavitt, S. W., Follett, R. F., and Paul, E. A.: Estimation of slow- and fast-cycling soil organic carbon pools from $6 \mathrm{~N} \mathrm{HCl}$ hydrolysis, Radiocarbon, 38, 231-239, 1996.

Perez, G., Aubert, M., Decaens, T., Trap, J., and Chauvat, M.: Home-Field Advantage: A matter of interaction between litter biochemistry and decomposer biota, Soil Biol. Biochem., 67, 245-254, 2013.

Rosberg, I., Ovstedal, D. O., Seljelid, R., Schreiner, O., and Goksoyr, J.: Estimation of carbon flow in a Calluna Heath System, Oikos, 37, 295-305, 1981.

Safarík, I. and Santrucková, H.: Direct determination of total soil carbohydrate content, Plant Soil, 143, 109-114, 1992.

Scheffer, R. A., van Logtestijn, R. S. P., and Verhoeven, J. T. A.: Decomposition of Carex and Sphagnum litter in two mesotrophic fens differing in dominant plant species, Oikos, 92, 44-54, 2001.

Schmidt, M. W. I., Torn, M. S., Abiven, S., Dittmar, T., Guggenberger, G., Janssens, I. A., Kleber, M., Kögel-Knabner, I., Lehmann, J., Manning, D. A. C., Nannipieri, P., Rasse, D. P., Weiner, S., and Trumbore, S. E.: Persistence of soil organic matter as an ecosystem property, Nature, 478, 49-56, 2011.

Skjemstad, J. O., Clarke, P., Taylor, J. A., Oades, J. M., and Newman, R. H.: The removal of magnetic-materials from surface soils - A solid-state C-13 Cp/Mas nmr-study, Aust. J. Soil Res., 32, 1215-1229, 1994.

Soil Survey Staff: Keys to Soil Taxonomy, 11th Edn., USDA Natural Resources Conservation Service, Washington, DC, 2010.
Strand, L. T., Abrahamsen, G., and Stuanes, A. O.: Leaching from organic matter-rich soils by rain of different qualities: I. Concentrations, J. Environ. Qual., 31, 547-556, 2002.

Strand, L. T., Haaland, S., Kaste, Ø., and Stuanes, A. O.: Natural variability in soil and runoff from small headwater catchments at Storgama, Norway, Ambio, 37, 18-28, 2008.

Stuanes, A. O., de Wit, H. A., Hole, L. R., Kaste, O., Mulder, J., Riise, G., and Wright, R. F.: Effect of climate change on flux of $\mathrm{N}$ and C: Air-land-freshwater-marine links: Synthesis, Ambio, 37, 2-8, 2008.

Taylor, K., Rowland, A. P., and Jones, H. E.: Molinia caerulea (L.) Moench, J. Ecol., 89, 126-144, 2001.

Trumbore, S.: Age of soil organic matter and soil respiration: Radiocarbon constraints on belowground C dynamics, Ecol. Appl., 10, 399-411, 2000.

Trumbore, S.: Radiocarbon and soil carbon dynamics, Annu. Rev. Earth Pl. Sc., 37, 47-66, 2009.

van Vuuren, M. M. I. and Berendse, F.: Changes in soil organicmatter and net nitrogen mineralization in heathland soils, after removal, addition or replacement of litter from Erica-tetralix or Molinia-caerulea, Biol. Fert. Soils, 15, 268-274, 1993.

van Vuuren, M. M. I. and van der Eerden, L. J.: Effects of 3 rates of atmospheric nitrogen deposition enriched with n-15 on litter decomposition in a heathland, Soil Biol. Biochem., 24, 527-532, 1992.

Vestgarden, L. S., Austnes, K., and Strand, L. T.: Vegetation control on DOC, DON and DIN concentrations in soil water from a montane system, southern Norway, Boreal Environ. Res., 15, 565-578, 2010.

von Lützow, M., Kögel-Knabner, I., Ekschmitt, K., Flessa, H., Guggenberger, G., Matzner, E., and Marschner, B.: SOM fractionation methods: Relevance to functional pools and to stabilization mechanisms, Soil Biol. Biochem., 39, 2183-2207, 2007.

Wang, Q. K., Zhong, M., and He, T.: Home-field advantage of litter decomposition and nitrogen release in forest ecosystems, Biol. Fert. Soils, 49, 427-434, 2013.

Wickland, K. P., Neff, J. C., and Harden, J. W.: The role of soil drainage class in carbon dioxide exchange and decomposition in boreal black spruce (Picea mariana) forest stands, Can. J. Forest Res., 40, 2123-2134, 2010. 